\title{
Die Haftung von Ratingagenturen nach deutschem, französischem, englischem und europäischem Recht
}

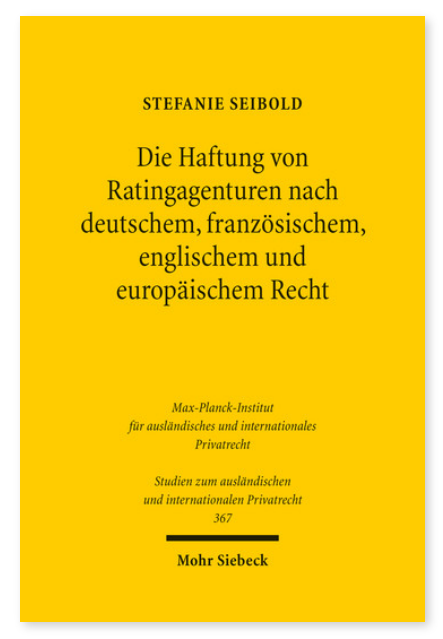

2016. XXI, 240 Seiten. StudIPR 367

ISBN 978-3-16-154586-3

eBook PDF $74,00 €$

ISBN 978-3-16-154585-6

fadengeheftete Broschur 74,00€

Seit der weltweiten Finanzkrise im Jahr 2008 wird eine intensive Diskussion um notwendige Maßnahmen zur Begrenzung der Marktmacht von Ratingagenturen geführt. Ein zentrales Element bildet hierbei die Frage nach ihrer Haftung für fehlerhafte Ratings, welche Stefanie Seibold für drei wichtige Mitgliedstaaten der Europäischen Union umfassend rechtsvergleichend analysiert: Ausgehend von den bestehenden europäischen Vorschriften zur Regulierung und Haftung von Ratingagenturen beleuchtet sie die Haftungsfrage sowohl gegenüber Emittenten beim Auftragsrating bzw. beim auftragslosen Rating als auch gegenüber sämtlichen Anlegergruppen nach deutschem, englischem und französischem Recht. Des Weiteren wird der Einfluss des Art. 35a der Verordnung (EU) Nr. 462/2013 auf die gefundenen Ergebnisse untersucht und die Frage nach dem Erfordernis weiterer Harmonisierungsmaßnahmen in Bezug auf die Haftung von Ratingagenturen gestellt.

Stefanie Seibold Geboren 1986; Studium der Rechtswissenschaft an der Friedrich-Alexander-Universität Erlangen-Nürnberg; Rechtsreferendariat am Oberlandesgericht Nürnberg; Wissenschaftliche Mitarbeiterin am Fachbereich Rechtswissenschaft der Universität Erlangen-Nürnberg; 2015 Promotion; derzeit Juristin in der Bayerischen Finanzverwaltung.

\section{Jetzt bestellen:}

https://mohrsiebeck.com/buch/die-haftung-von-ratingagenturen-nach-deutschem-franzoesischem-englischem-undeuropaeischem-recht-9783161545863?no_cache=1

order@mohrsiebeck.com

Telefon: +49 (0)7071-923-17

Telefax: $+49(0) 7071-51104$ 